\title{
Influence of the Spray Scrubber Geometry on the Efficiency of Dust Removal - Theoretical Predictions and CFD Analysis
}

\author{
A. Tomaszewski, T. Przybylinski ${ }^{\dagger}$, P. Kapica and M. Lackowski \\ Institute of Fluid Flow Machinery, Polish Academy of Sciences, Gdansk, 80-231, Poland \\ †Corresponding Author Email: tprzybylinski@imp.gda.pl
}

(Received September 2, 2019; accepted December 28, 2019)

\begin{abstract}
The article presents a method of purification of synthesis gas (syngas) produced as a result of biomass gasification with the use of a spray scrubber. The authors focus on the presentation of how individual elements of the geometry of a spray scrubber can influence its particle removal efficiency. The paper examines cases of dry particle removal, the use of demisters in purification process and wet scrubber collection efficiency with the use of numerical fluid mechanics (CFD). General equations are also used by authors to determine the initial predictions. The key part of the article is to present the results of the velocity and pressure distribution depending on the scrubber construction, determine the effect of the number of demisters used on the particle removal efficiency and to determine the probability of coalescence depending on the size of liquid droplets. Moreover, the authors formulate a simplified formula for the collection efficiency of a scrubber which is consistent with the results obtained from CFD calculations. The numerical results of collection efficiency were compared with experimental data from literature.
\end{abstract}

Keywords: Spray scrubbers; Wet scrubbers; Collection efficiency of scrubbers; Syngas purification.

\section{NOMENCLATURE}

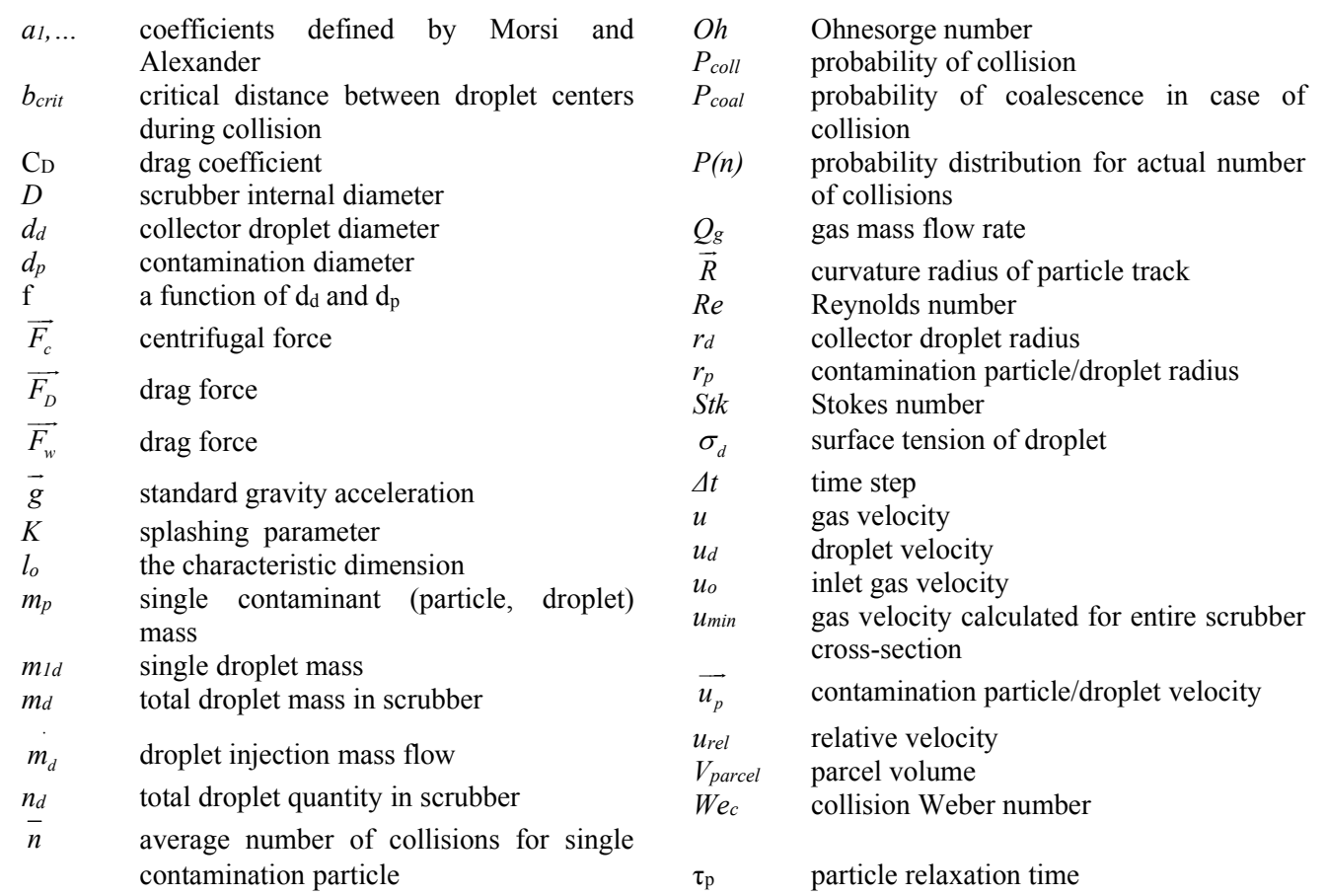


A. Tomaszewski et al. / JAFM, Vol. 13, No. 4, pp. 1055-1066, 2020.

$\begin{array}{ll}\tau_{\mathrm{D}} & \text { characteristic time of flow } \\ \Delta \tau & \text { droplet injection time } \\ \mu_{g} & \text { gas dynamic viscosity } \\ \mu_{d} & \text { liquid dynamic viscosity } \\ \rho & \text { gas density }\end{array}$

\section{INTRODUCTION}

The spray tower scrubber is the common type of wet scrubber that removes impurities and dust from gases that are readily soluble in the spray liquid absorbent (Schifftner 1996). That is why this kind of scrubber is proposed in literature for desulphurization (Yeh and Rochelle 2003; Codolo and Bizzo 2013; Marocco and Inzoli 2009; Zhen et al. 2017), denitrification (Jafari et al. 2018; Javed et al. 2006) or, recently, even to remove carbon dioxide (Kuntz and Aroonwilas 2009; Koller et al. 2011).

The key mechanism of gas cleaning in spray tower scrubbers is the phenomenon of inertia collision and direct coupling of gas particles with the surface of falling droplets, which was extensively described in the literature (Schifftner 1996; Svarovsky 1981; Warych 1998). The amount of gas absorbed rises with increase of the contact time between the phases and with the energy used to create the absorbent surface. Contact time of the phases depends on the process of mass transfer between the flowing gases and the droplets of the spray liquid. It can take place in counter-current or co-current flow, cross-flow or reverse flow (Warych 1998). Typical efficiencies of spray tower scrubbers are $90 \%$ for particles greater than $5 \mu \mathrm{m}, 60-80 \%$ for particulates 3-5 $\mu \mathrm{m}$ and $40-50 \%$ or less for submicron particulates (Schifftner 1996).

In the literature, much works has been focused on checking the effect of spray droplets on the effectiveness of particle removal. Koller et al. (2011) and Kuntz et al. (2009) checked how droplet sizes can contribute to the removal of $\mathrm{CO}_{2}$. In addition, Koller et al. (2011), Jafari et al. (2018), Codolo and Bizzo (2013) presented the effect of the number of nozzles on the speed of dirt removal. Codolo and Bizzo (2013), during testing the $\mathrm{SO}_{2}$ removal efficiency, drew the following conclusion the removal efficiency is dependent on the diameter of the nozzle opening. If the nozzle opening is larger the efficiency is lower and vice versa. They also noticed that increasing the superficial liquid velocity using a given nozzle orifice diameter heightened the removal efficiency. Codolo and Bizzo (2013) also suggest that the number of spray nozzles employed can also affect the removal efficiency, because it changes the coverage of the volume of the tower by the droplets. Jafari et al. (2018) demonstrated that working pressure plays an important role in removing contaminants, and Wang et al. (2019) showed that an increase in spray density particularly affects the effective removal of small particles (less than $10 \mu \mathrm{m}$ ). Works (Marocco and Inzoli 2009; Wrzesinska and Witman 2009) presented how the ratio of volume of liquid to

$\begin{array}{ll}\rho_{d} & \text { droplet density } \\ \rho_{p} & \text { contamination particle density } \\ \eta d_{r y} & \text { scrubber dry collection efficiency } \\ \eta_{w e t} & \text { scrubber wet collection efficiency }\end{array}$

volume of gas at given levels of the tower affects the efficiency. Moreover, in the paper (Zhen et al. 2017) there were conducted studies on the influence of the deflectors used in the scrubber's construction on its particle removal efficiency and droplet concentration.

Spray scrubbers can be used to purify synthesized gas (syngas), which is produced as a result of biomass gasification and contains impurities in the form of tar containing nitrogen based compounds ( $\mathrm{NH}_{3}, \mathrm{HCN}$, etc.), sulphur based compounds $\left(\mathrm{H}_{2} \mathrm{~S}\right.$, $\mathrm{COS}$, etc.), hydrogen halides ( $\mathrm{HCl}, \mathrm{HF}$, etc.) and trace metals ( $\mathrm{Na}, \mathrm{K}$, etc.) (Woolcock and Brown 2013; Abdoulmouminea et al. 2015). Syngas can be used in low power cogeneration systems as a fuel in piston engines and gas turbines. However, it must satisfy certain purity requirements presented in (Woolcock and Brown 2013; Abdoulmouminea et al. 2015). From a technical point of view, condensing tar can block pipes and damage engines and turbines, while nitrogen, sulphur and chlorine compounds are corrosive. So cleaning the syngas is necessary.

Due to the fact that in the literature there are few works on the influence of spray scrubber geometry on its efficiency, it was decided to analyze individual elements of such scrubber and check how they influence its efficiency.

\section{NUMERICAL MODEL}

\subsection{The Assumptions}

The first objective of the numerical analysis was to create a computational model of the spray scrubber with optimal geometry, which then could be used for experimental tests. The simplest (reference) geometry of the scrubber is presented in Fig. 1, in which no mist eliminator was used and no liquid injection was provided. Other geometries, which will be used during the research, contain demisters. Position of the demisters is shown in Fig. 2.

Usually, after the process of biomass gasification, the exhaust gases are flowing through the cooler. In the considered case the syngas temperature on scrubber's inlet is expected to be below $50{ }^{\circ} \mathrm{C}$. It was assumed that the relative humidity on the scrubber inlet is on the high level and therefore evaporation of droplets was not included in the numerical model. In the cases shown in Fig. 1 and Fig. 2a, the liquid injection was not used. Only solid silica particles were introduced on the inlet. The particle removal process in the model was carried out under dry conditions to make sure which of the cases has optimal dry collection efficiency. After that, the tests with demisters and liquid injection (see Fig. 2b) were carried out. 
A. Tomaszewski et al. / JAFM, Vol. 13, No. 4, pp. 1055-1066, 2020.

Table 1 Operating parameters of scrubbers available in literature

\begin{tabular}{|c|c|c|c|c|c|c|}
\hline Literature & $\begin{array}{l}\text { Codolo } \\
\text { and } \\
\text { Bizzo } \\
(2013)^{1}\end{array}$ & $\begin{array}{l}\text { Marocco and } \\
\text { Inzoli }(2009)^{2}\end{array}$ & $\begin{array}{l}\text { Marocco } \\
(2010)^{2}\end{array}$ & $\begin{array}{l}\text { Zhen et al. } \\
(2017)^{3} \text { - test } \\
\text { conditions }\end{array}$ & $\begin{array}{c}\text { Zhen et al. } \\
(2017)^{3}\end{array}$ & $\begin{array}{l}\text { Jafari et al. } \\
\quad(2018)^{1}\end{array}$ \\
\hline Operating gas & $\mathrm{SO}_{2}$ & $\mathrm{SO}_{2}$ & $\mathrm{SO}_{2}$ & $\mathrm{SO}_{2}$ & $\mathrm{SO}_{2}$ & $\mathrm{NH}_{3}$ \\
\hline Removal efficiency [\%] & $48 \div 100$ & $20 \div 85$ & - & - & $89.6 \div 98.5$ & $82 \div 98$ \\
\hline $\begin{array}{l}\text { Gas velocity in the tower } \\
{[\mathrm{m} / \mathrm{s}]}\end{array}$ & $0.4 \div 1.6$ & $0 \div 6.2$ & - & $0 \div 10$ & 3.48 & 1.27 \\
\hline Gas flow rate $\left[\mathrm{m}^{3} / \mathrm{s}\right]$ & $\begin{array}{l}2.64 \div \\
10.57\end{array}$ & 1.68 & 936.58 & $0.9 \div 2.11$ & 477 & 6.3 \\
\hline Liquid flow rate $\left[\mathrm{m}^{3} / \mathrm{s}\right]$ & $\begin{array}{c}2.22 \div \\
5.56\end{array}$ & 6.7 & 1.9 & $6.7 \div 2.5$ & - & 1 \\
\hline $\begin{array}{l}\text { Liquid to gas ratio } \mathrm{L} / \mathrm{G} \\
\qquad\left[1 / \mathrm{m}^{3}\right]\end{array}$ & - & - & - & $10 \div 20$ & $11.6,20$ & - \\
\hline $\begin{array}{l}\text { Number of injection } \\
\text { points/nozzles }\end{array}$ & $1 \div 5$ & 300 & 40 & 84 & 248 & $1 \div 3$ \\
\hline $\begin{array}{c}\text { Orifice nozzle diameter } \\
{[\mathrm{m}]}\end{array}$ & $2.4 \div 5.6$ & - & - & - & - & - \\
\hline $\begin{array}{l}\text { Diameter of the tower } \\
{[\mathrm{m}]}\end{array}$ & 0.29 & 1.5 & 18.29 & 1.2 & 13.3 & 0.25 \\
\hline Height of the tower [m] & 1.5 & 6.8 & 45.42 & 4.08 & 33.41 & 1.38 \\
\hline Literature & $\begin{array}{c}\text { Javed et } \\
\text { al. } \\
(2006)^{1}\end{array}$ & Kuntz et al.(2009) & $\begin{array}{c}\text { Koller et } \\
\text { al. }(2011)^{1}\end{array}$ & \multicolumn{2}{|c|}{ Wang et al. (2019) ${ }^{2}$} & $\begin{array}{l}\text { Wrzesinska } \\
\text { and } \\
\text { Witman } \\
(2009)^{1}\end{array}$ \\
\hline Operating gas & $\mathrm{NH}_{3}$ & $\mathrm{CO}_{2}$ & $\mathrm{CO}_{2}$ & \multicolumn{2}{|c|}{$\mathrm{NH}_{3}$} & $\begin{array}{l}\text { Silica fume } \\
\quad\left(\mathrm{SiO}_{2}\right)\end{array}$ \\
\hline Removal efficiency [\%] & - & - & $20 \div 78$ & \multicolumn{2}{|c|}{$10 \div 97$} & $18 \div 97$ \\
\hline $\begin{array}{l}\text { Gas velocity in the tower } \\
{[\mathrm{m} / \mathrm{s}]}\end{array}$ & $\begin{array}{c}0.43 \div \\
1.7\end{array}$ & - & $\begin{array}{c}2.5 \\
(0.7 \div 3.0) \\
4\end{array}$ & \multicolumn{2}{|c|}{$0.2 \div 3.0$} & $0.32 \div 0.64$ \\
\hline Gas flow rate $\left[\mathrm{m}^{3} / \mathrm{s}\right]$ & $\begin{array}{c}0.003 \div \\
0.013\end{array}$ & $\begin{array}{c}1.67 \cdot 10^{-3} \\
\left(764 \mathrm{~m}^{3} / \mathrm{m}^{2} \mathrm{~h}\right)\end{array}$ & up to 0.044 & \multicolumn{2}{|c|}{$\begin{array}{c}0.16 \div 2.36 \\
{\left[0.5 \div 2.5(\mathrm{~m} / \mathrm{s})\left(\mathrm{kg} / \mathrm{m}^{3}\right)^{0.5}\right]^{5}}\end{array}$} & $0.01 \div 0.015$ \\
\hline Liquid flow rate $\left[\mathrm{m}^{3} / \mathrm{s}\right]$ & $\begin{array}{c}3 \cdot 10^{-5} \div \\
8 \cdot 10^{-5}\end{array}$ & $\begin{array}{c}2.25 \cdot 10^{-5} \\
\left(10.3 \mathrm{~m}^{3} / \mathrm{m}^{2} \mathrm{~h}\right)\end{array}$ & $\begin{array}{l}\operatorname{up~to~}_{5.6 \cdot 10^{-4}}\end{array}$ & \multicolumn{2}{|c|}{$\begin{array}{c}6.3 \cdot 10^{-4} \div 1.73 \cdot 10^{-3} \\
\left(2.88 \div 7.92 \mathrm{~m}^{3} / \mathrm{m}^{2} \mathrm{~h}\right)\end{array}$} & $0 \div 2.7 \cdot 10^{-5}$ \\
\hline $\begin{array}{l}\text { Liquid to gas ratio } \mathrm{L} / \mathrm{G} \\
\qquad\left[1 / \mathrm{m}^{3}\right]\end{array}$ & 10 & 13.5 & $0 \div 34$ & \multicolumn{2}{|c|}{$0.7 \div 4$} & - \\
\hline $\begin{array}{l}\text { Number of injection } \\
\text { points/nozzles }\end{array}$ & 1 & 1 & 2 & \multicolumn{2}{|l|}{-} & 1 \\
\hline $\begin{array}{l}\text { Orifice nozzle diameter } \\
{[\mathrm{m}]}\end{array}$ & - & - & - & \multicolumn{2}{|l|}{-} & - \\
\hline $\begin{array}{c}\text { Diameter of the tower } \\
{[\mathrm{m}]}\end{array}$ & 0.1 & 0.1 & - & \multicolumn{2}{|c|}{1} & 0.2 \\
\hline Height of the tower [m] & 1.25 & 0.55 & - & \multicolumn{2}{|c|}{2.5} & 0.5 \\
\hline
\end{tabular}




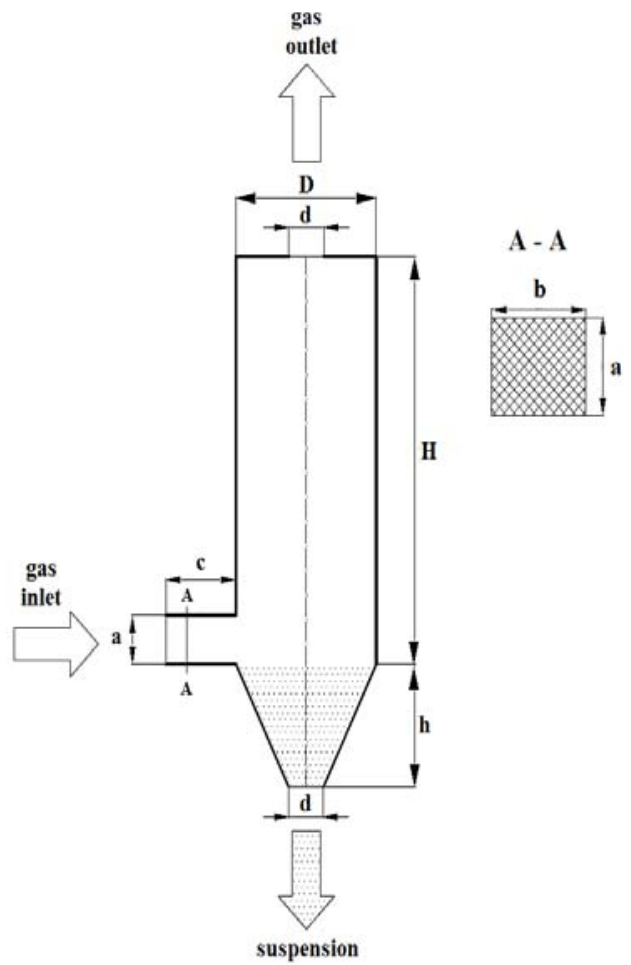

Fig. 1. Basic geometry (reference case) of numerical model.
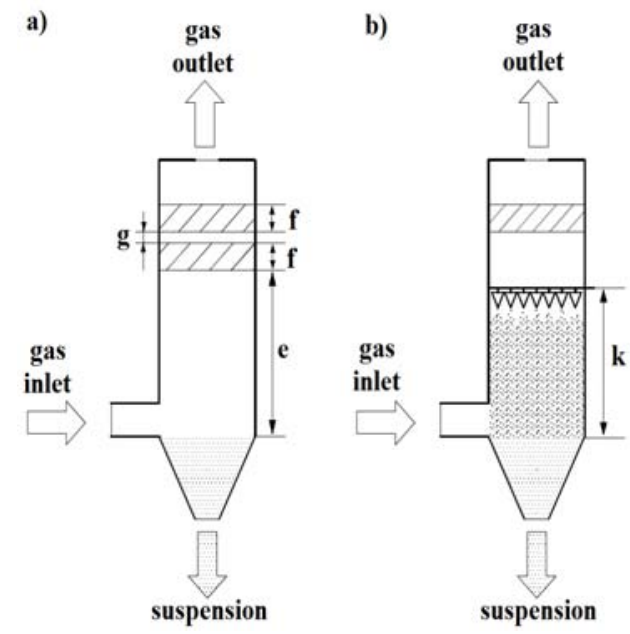

Fig. 2. Geometry of the models with: a) double demister, b) demister and liquid injection.

The dimensions of the scrubber models are presented in the Table 2 .

\subsection{Preliminary Prediction of Terminal Velocity.}

Theoretical predictions of velocity at the scrubber inlet $u_{0}$, based on the gas flow rate $\dot{Q}_{G}$ of $36 \mathrm{~m}^{3} / \mathrm{h}$ and the geometrical dimensions, follow from the continuity equation in the form

$$
u_{o}=\frac{Q_{G}}{a b}
$$

Table 2 Dimensions of simple geometry models (see Fig.1 and 2)

\begin{tabular}{|c|c|}
\hline $\mathrm{H}[\mathrm{mm}]$ & 500 \\
\hline $\mathrm{D}[\mathrm{mm}]$ & 200 \\
\hline $\mathrm{d}[\mathrm{mm}]$ & 50 \\
\hline $\mathrm{a}[\mathrm{mm}]$ & 60 \\
\hline $\mathrm{b}[\mathrm{mm}]$ & 40 \\
\hline $\mathrm{c}[\mathrm{mm}]$ & 100 \\
\hline $\mathrm{h}[\mathrm{mm}]$ & 150 \\
\hline $\mathrm{e}[\mathrm{mm}]$ & 300 \\
\hline $\mathrm{f}[\mathrm{mm}]$ & 50 \\
\hline $\mathrm{g}[\mathrm{mm}]$ & 20 \\
\hline $\mathrm{k}[\mathrm{mm}]$ & 280 \\
\hline
\end{tabular}

Minimal velocity of gas flow in the scrubber can be determined from the relations:

$\dot{Q}=$ const. $\Rightarrow \dot{Q}_{2}=\dot{Q}_{G}$

$\dot{Q}_{2}=\frac{\pi D^{2}}{4} u_{\text {min }}$

So it follows that

$u_{\min }=\frac{4 \dot{Q}_{G}}{\pi D^{2}}$

It can be stated that the minimum velocity of gas flow in the scrubber $u_{\min }$ (calculated from Eqs. 2 4) will be about $0.318 \mathrm{~m} / \mathrm{s}$ and inlet velocity of scrubber $u_{o}$ will be about $4.18 \mathrm{~m} / \mathrm{s}$.

Based on the assumed minimum velocity $u_{\min }$, the physical parameters of the air (for temperature 15 ${ }^{\circ} \mathrm{C}$ and pressure $1013.25 \mathrm{hPa}$ ) and geometrical dimensions of scrubbers, the calculated Reynolds number,

$$
\operatorname{Re}=\frac{\rho \cdot u_{\min } \cdot D}{\mu}
$$

is expected to be around 4500 . Therefore, even in the biggest cross section of the scrubber, the turbulent flow is expected.

In addition, the Stokes number (Eq. 6) can be calculated for the particle diameters given in the Table 3 and for the physical parameters of the air (for temperature $15{ }^{\circ} \mathrm{C}$ and pressure $1013.25 \mathrm{hPa}$ ). The Stokes number gives a measure of temporal correlation between the velocities of the particle and the fluid. In the cases considered here, Stokes numbers are definitely lower than 1 , what means that the particles follow the bulk macroscopic flow and do not affect the fluid flow field. Table 3 also shows the terminal velocity values $u_{t}$ for the respective particle diameters, which are calculated from relation (9) for silica dust which density 
equals to $2650 \mathrm{~kg} / \mathrm{m}^{3}$. The terminal velocities achieved are very low, which indicates that the dust particles are carried away by the gas stream. Therefore, gravitational separation may be hardly effective in this case. Stokes number is the ratio between particle relaxation time and characteristic time of flow,

$$
S t k=\frac{\tau_{p}}{\tau_{D}}
$$

where

$$
\begin{aligned}
& \tau_{p}=\frac{\rho_{p} \cdot d_{p}^{2}}{18 \mu_{g}} \\
& \tau_{D}=\frac{l_{o}}{u_{o}} \\
& u_{t}=\frac{d_{p}{ }^{2}\left(\rho_{p}-\rho_{g}\right) g}{18 \mu_{g}}
\end{aligned}
$$

Table 3 Stokes number and terminal velocity values for selected particle sizes

\begin{tabular}{|c|c|c|c|c|c|}
\hline $\mathrm{d}_{\mathrm{p}}[\mu \mathrm{m}]$ & $\begin{array}{c}\mathrm{u}_{\mathrm{t}} \\
10^{-3} \\
{[\mathrm{~m} / \mathrm{s}]}\end{array}$ & $\begin{array}{c}\mathrm{Stk} \\
10^{-3}\end{array}$ & $\mathrm{~d}_{\mathrm{p}}[\mu \mathrm{m}]$ & $\begin{array}{c}\mathrm{u}_{\mathrm{t}} \\
10^{-3} \\
{[\mathrm{~m} / \mathrm{s}]}\end{array}$ & $\begin{array}{c}\mathrm{Stk} \\
10^{-3}\end{array}$ \\
\hline 1 & 0.085 & 0.18 & 11 & 10 & 21.9 \\
\hline 2 & 0.34 & 0.72 & 12 & 12 & 26.1 \\
\hline 3 & 0.76 & 1.63 & 13 & 14 & 30.6 \\
\hline 4 & 1.4 & 2.9 & 14 & 17 & 35.5 \\
\hline 5 & 2.1 & 4.53 & 15 & 19 & 40.7 \\
\hline 6 & 3 & 6.52 & 1 & 22 & 46.3 \\
\hline 7 & 4.1 & 8.87 & 17 & 24 & 52.3 \\
\hline 8 & 5.4 & 11.6 & 18 & 27 & 58.6 \\
\hline 9 & 6.9 & 14.7 & 19 & 30 & 65.3 \\
\hline 10 & 8.5 & 18.1 & 20 & 34 & 72.4 \\
\hline
\end{tabular}

Table 4 Terminal velocity values for water collector droplets of bigger diameter

\begin{tabular}{|c|c|c|}
\hline $\begin{array}{c}\text { droplet diameter } \\
{[\mu \mathrm{m}]}\end{array}$ & $\begin{array}{c}\text { terminal } \\
\text { velocity }[\mathrm{m} / \mathrm{s}]\end{array}$ & $\begin{array}{c}\text { Stokes } \\
\text { number } \\
{[-]}\end{array}$ \\
\hline 40 & 0.05 & 0.29 \\
\hline 60 & 0.11 & 0.65 \\
\hline 80 & 0.2 & 1.16 \\
\hline 100 & 0.32 & 1.81 \\
\hline 125 & 0.5 & 2.83 \\
\hline 150 & 0.72 & 4.07 \\
\hline 175 & 0.98 & 5.54 \\
\hline 200 & 1.27 & 7.24 \\
\hline
\end{tabular}

Further analysis was performed for the case with water droplet injection. The terminal velocity of water droplets have been calculated for several droplet diameters (Table 4). The values of terminal velocity for water collector droplets are much higher than for smaller dust particles, however there is still a possibility that droplets of $100 \mu \mathrm{m}$ diameter, or even higher, will be carried by the gas flow to the outlet.

\subsection{Description of the Numerical Model}

The fluid dynamics inside spray scrubber can be modelled using Euler-Lagrangian approach (Marocco and Inzoli 2009; Wang et al. 2019; Lapin and Lübbert 1994). The continuous gas phase is solved with Eulerian approach while the particles of contamination are modelled as a dispersed phase in Lagrangian frame. In such approach, which is adopted in this study, there is only one way of coupling between these two phases. Namely, the fluid affects the momentum of the droplet or particle but the fluid flow remains unaffected by the droplet movement. Such simplification is reasonable for the low Stokes numbers and leads to significant reduction of mesh size and, in consequence, of computational time. Energy equation is not taken into account because the main purpose of the research is to investigate dynamics between the fluid and dispersed phase. In order to make the calculations more efficient, firstly only the gas flow (without any particles) is solved and then the obtained steady solution is implemented as an initial condition to further unsteady calculations, which include the presence of droplets or particles. The calculations have been performed on fluid which had the properties of dry air in normal conditions. In all of the cases, there are two phases in the model - one continuous gas phase and one dispersed phase. In the preliminary calculations without droplet injection, the solid silica particles were introduced on the inlet. In the second case, with water droplet injection, the contamination particles were replaced by water droplets of the same size. It was caused by the limitations of the used Discrete Phase Model (DPM) implementation. Namely, coalescence cannot be enabled when there are two or more different materials in dispersed phase. Both approaches returned results, which are in good agreement with experimental data (see Fig. 13).

\subsection{Forces Affecting Particles and Droplets}

The particles of contaminations are assumed to have spherical shape and their diameter distribution on inlet ranges from $1 \mu \mathrm{m}$ to $20 \mu \mathrm{m}$, while the water droplets injected from the nozzle have uniform diameter (100-200 $\mu \mathrm{m}$ depending on the computational case). The density ratio of the gas to the water droplets and solid particles is very low and therefore the Basset force, the pressure gradient force and the virtual mass force have negligible values and could be not included in the model. In such case, there are only a few forces which affect the particle/droplet movement in a significant way, namely the drag, centrifugal, mass and buoyancy forces.

When particle velocity is different compared to gas velocity field, then the drag force appears. The drag force, adopted in this research is represented by the following equation: 
$\overrightarrow{F_{D}}=m_{p} \frac{18 \mu}{\rho_{g} d_{p}{ }^{2}} \frac{C_{D} \operatorname{Re}}{24}\left(\vec{u}-\overrightarrow{u_{p}}\right)$

where Reynolds number is defined as

$$
\operatorname{Re}=\frac{\rho d_{p}\left|\vec{u}-\overrightarrow{u_{p}}\right|}{\mu}
$$

and the drag coefficient is evaluated by method proposed by Morsi and Alexander (1972), where $\mathrm{a}_{1}$, $\mathrm{a}_{2} \mathrm{a}_{3}$ are the coefficients defined by these authors,

$C_{D}=a_{1}+\frac{a_{2}}{\mathrm{Re}}+\frac{a_{3}}{\mathrm{Re}^{2}}$

The centrifugal force is given by:

$\overrightarrow{F_{C}}=\frac{m_{p} \overrightarrow{u_{p}^{2}}}{\vec{R}}$

The difference between buoyancy and gravity force:

$$
\overrightarrow{F_{w}}=m_{p} \frac{\vec{g}\left(\rho_{p}-\rho\right)}{\rho_{p}}
$$

\subsection{The Mechanism of Collision and Coalescence}

The separation inside scrubber is enhanced by water droplet injection through the nozzle. Larger water droplets should coalescence with smaller, solid particles and separate gravitationally from the fluid flow. In the numerical simulation, particle and droplet trajectories are solved simultaneously. The collision should occur if the distance between droplet centers is smaller than the sum of their radii, $\mathrm{r}_{\mathrm{p}}+\mathrm{r}_{\mathrm{d}}$. However, implementing such procedure in numerical solution will result in huge computational effort. Therefore, the stochastic algorithm of O'Rourke (1981) was used. The particles are grouped in bigger agglomerations called parcels and the computational solver only needs to calculate their trajectories. The model estimates the probability of the collision of adjacent parcels, which is dependent from droplet quantity, size and velocity. According to O'Rourke (1981), the probability of collision of two droplets can be found from the equation:

$$
P_{\text {coll }}=\frac{\pi\left(r_{p}+r_{d}\right)^{2} u_{r e l} \Delta t}{V_{\text {parcel }}}
$$

Probability of collision of two particles, during the defined period of time $\Delta t$, depends on the particle dimensions, their relative velocity and the volume in which the phenomenon is considered. The Equation (15) can be either generalized for parcels (this takes place during the numerical simulation process) or for the entire volume of scrubber (in which the collisions take place) in order to estimate the separation efficiency. The second approach is presented below and the Eq. (16) indicates the expected mean number of collisions for a single dust particle flowing through the cloud of droplets. $\bar{n}=\frac{n_{d} \pi\left(r_{1}+r_{2}\right)^{2} H}{\pi R^{2} H}=\frac{n_{d}\left(d_{p}+d_{d}\right)^{2}}{D^{2}}$

Where the number of droplets in the cloud is equal to the ratio of injected water mass to the mass of single droplet:

$n_{d}=\frac{m_{d}}{m_{1 d}}=\frac{6 m_{d} \Delta \tau}{\pi d_{d}{ }^{3} \rho_{d}}$

However, the mean number of collisions is not the same as exact number of collisions. The probability of the exact number of collisions for a single dust particle, according to O'Rourke is described by the Poisson distribution:

$P(n)=e^{-\bar{n}} \frac{n^{\bar{n}}}{n !}$

In particular, the probability that a dust particle will flow through the entire cloud of droplets without any collision is given by:

$P(0)=e^{-\bar{n}}$

The scrubber dry collection quantitative efficiency can be measured experimentally or obtained from CFD calculations as a ratio of the quantity of collected dust particles to their total quantity introduced to the system. If the scrubber dry collection quantitative efficiency is known then the quantitative efficiency for the wet case with droplets included can be estimated as:

$\eta_{w e t}=1-\left(1-\eta_{d r y}\right) e^{-\bar{n}}$

In this equation the fraction of contamination that is not separated by the scrubber geometry is multiplied by the probability of flowing through the cloud of droplets for single particle, which indicates the fraction of contamination that will flow through the outlet during wet scrubber particle removal process. Then all other particles are treated as collected.

When it is determined that two parcels will collide, there are some further outcomes possible, like coalescence and bouncing. According to the model, the coalescence should take place when the droplets collide head on and the distance between their centers is below the critical value determinate by equation:

$b_{c r i t}=\left(r_{p}+r_{d}\right) \sqrt{\min \left(1.0 ; \frac{2.4 f}{W e_{c}}\right)}$

Where $\mathrm{f}$ is the function of droplet radii,

$f\left(\frac{r_{d}}{r_{p}}\right)=\left(\frac{r_{d}}{r_{p}}\right)^{3}-2.4\left(\frac{r_{d}}{r_{p}}\right)^{2}+2.7\left(\frac{r_{d}}{r_{p}}\right)$

and the collision Weber number is equal to

$W e_{c}=\frac{\rho u_{r e l}^{2} d_{a v g}}{\sigma}$ 
So, the probability of coalescence equals to

$$
P_{\text {coal }}=\frac{\pi b_{\text {crit }}{ }^{2}}{\pi\left(r_{p}+r_{d}\right)^{2}}=\sqrt{\min \left(1.0 ; \frac{2.4 f}{W e_{c}}\right)}
$$

In Fig. 3, the estimated probability of coalescence as a result of collision is presented according to O'Rourke (1981) algorithm for different smaller droplet diameters, different collector water droplet diameters and relative velocity $10 \mathrm{~m} / \mathrm{s}$.

These results show that the coalescence should always appear for collector droplets of diameter 80 $\mu \mathrm{m}$ or larger. The other outcome of a collision can be a reflection - if the distance between two centers is more than the critical value, which is possible for smaller collector droplets.

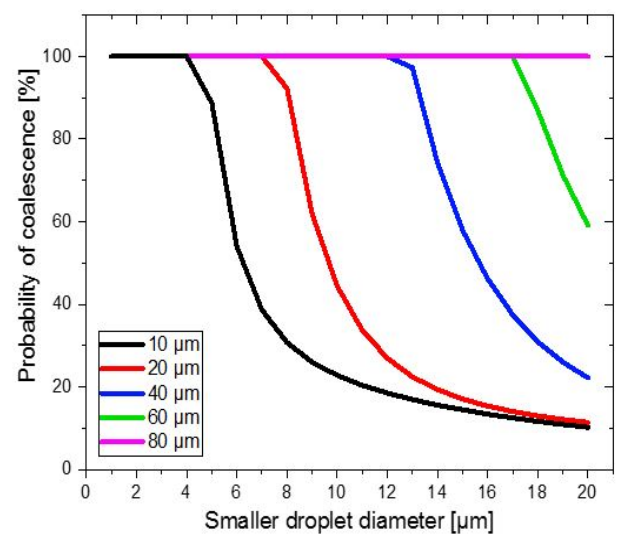

Fig. 3. Probability of coalescence as a result of smaller water droplet collision with collector droplet.

\subsection{Contact of Particle/Droplet with Wall}

When liquid droplets collide with a wall, different phenomena like deposition, rebound or splash may occur. The condition for the deposition, reflection or splashing of droplets is the parameter $K$ (being a function of Reynolds and Ohnesorge numbers), presented by Mundo et al. (1994).

$K=\mathrm{Re}^{1.25} \cdot O h$

where

$\operatorname{Re}=\frac{\rho_{d} d_{d} u_{d}}{\mu_{d}}$

$O h=\frac{\mu_{d}}{\sqrt{\rho_{d} d_{d} \sigma_{d}}}$

Introducing (26) and (27) into (25) the final form of parameter $K$ is obtained:

$K=\frac{\left(\rho_{d} d_{d}\right)^{\frac{3}{4}} \cdot u_{d}^{\frac{5}{4}}}{\sigma_{d}^{\frac{1}{2}} \cdot \mu_{d}^{\frac{1}{4}}}$

If the $K$ parameter is lower than the critical value of $K_{\text {crit. }}<57.7$ the droplets are completely embedded on the wall without bouncing or breaking. Then the kinetic energy of the droplet is dispersed, regardless of the roughness of the wall. However, if the parameter $K$ exceeds the value of 57.7 the droplets are reflected and broken. For conditions expected to appear in the model simulations, the value of parameter $K$ is equal 48 and is below the critical (for the maximal droplet size of $200 \mu \mathrm{m}$ and for maximal expected velocity of $5 \mathrm{~m} / \mathrm{s}$ ). The maximum expected velocity value is assumed to be $5 \mathrm{~m} / \mathrm{s}$ as this value was one of the highest gas stream velocities in the spray scrubber in the preliminary CFD calculations (see in Fig. 5b and $6 b)$. Due to this, the reflection boundary condition with total extinction of both velocity components was set. It means that the droplet trajectory will still be calculated after a contact with the wall. However, the process of liquid film formation was not considered in the model to maintain its simplicity.

\subsection{Boundary Conditions}

The boundary conditions used in the model are presented in Tab. 5. The locations are shown in Fig. 2. Both the inlet/outlet boundary conditions are listed as well as the behavior of droplet/particle in contact with the specified walls.

Table 5 Boundary conditions of the numerical model

\begin{tabular}{|c|c|c|c|c|}
\hline location & inlet & gas outlet & $\begin{array}{c}\text { suspension } \\
\text { outlet }\end{array}$ & walls \\
\hline $\begin{array}{c}\text { boundary } \\
\text { condition }\end{array}$ & $\begin{array}{c}\text { mass } \\
\text { flow } \\
\text { inlet }\end{array}$ & $\begin{array}{c}\text { pressure } \\
\text { outlet }\end{array}$ & wall & wall \\
\hline $\begin{array}{c}\text { DPM } \\
\text { boundary } \\
\text { condition }\end{array}$ & escape & escape & trap & $\begin{array}{c}\text { reflect, } \\
\text { velocity } \\
\text { extinction }\end{array}$ \\
\hline
\end{tabular}

The values of mass flow rates, set in the calculations for gas flow, contamination and collector droplets are presented in Tab. 6 .

Table 6 Boundary conditions of the numerical model

\begin{tabular}{|c|l|c|c|}
\hline location & gas inlet & $\begin{array}{c}\text { contaminati } \\
\text { on inlet }\end{array}$ & $\begin{array}{c}\text { water } \\
\text { injection }\end{array}$ \\
\hline $\begin{array}{l}\text { mass flow } \\
\text { rate }[\mathrm{kg} / \mathrm{s}]\end{array}$ & 0.01225 & 0.0001225 & $0-0.6126$ \\
\hline
\end{tabular}

\section{RESUlts OF DRY DUST EXTRACTION EFFICIENCY FOR DIFFERENT SCRUBBER GEOMETRIES}

Particle removal efficiency was tested for a flow rate of $36 \mathrm{~m}^{3} / \mathrm{h}$, which was also set during experimental measurements (Wrzesinska and Witman (2009)). The first tests of dust removal efficiency were started on a simple geometry of the scrubber (shown in Fig. 1). After that, the tests with single and double demister (Fig. 2) were performed. The calculated contours of pressure and velocity are shown in Fig. 5 and 6. In these simulations there were no droplets introduced to the system. The mass flow of injected dust silica was equal to $1 \%$ 
of air mass flow rate and was injected into the scrubber during a limited time interval in order to get reasonable computational time. In all of the computational cases, flow duration of $10 \mathrm{~s}$ after the dust injection was simulated. The particle content was sampled on several planes, located at different altitudes shown in Fig. 4 as well as on a plane just below the inlet and on both outlets. The collection efficiency was calculated by comparison of particles quantity registered on the inlet and outlet.

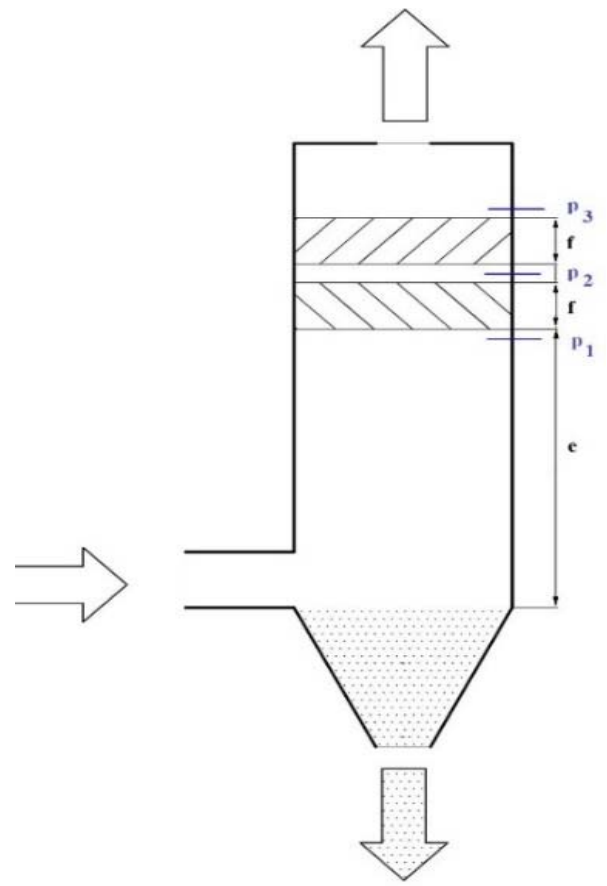

Fig. 4. Scrubber geometry with marked sample planes $p$, inlet and both outlets.

The results showed that the presence of two demister rows does not affect the pressure drop significantly. Then, the impact of demister quantity on separation efficiency was investigated. The results are presented in Fig. 7 and 8. It turned out that the geometry with a single demister leads to the highest dust collection efficiency without droplet injection. The introduction of two demisters causes that the gas, having a smaller, more limited flow space, accelerates at the outlet. The increase of gas velocity just before the exit from the scrubber is an undesirable phenomenon, which decreases dust extraction efficiency. The reason of such tendency can be explained with the help of Fig. 6b, where it is visible that the additional rows of demisters increase the flow velocity between demister vanes and particles are carried away by the flow. Due to centrifugal force, the air distribution is not uniform in every vane channel. The calculations showed that placing the third row of vanes enhances the air velocity even more in one side of peripheral area of demister and affects negatively the separation efficiency. In Fig. 6b, on the lower side of scrubber, there is visible increase in air velocity. It is caused by the presence of the air inlet placed nearby, behind the presented cross-section. a)

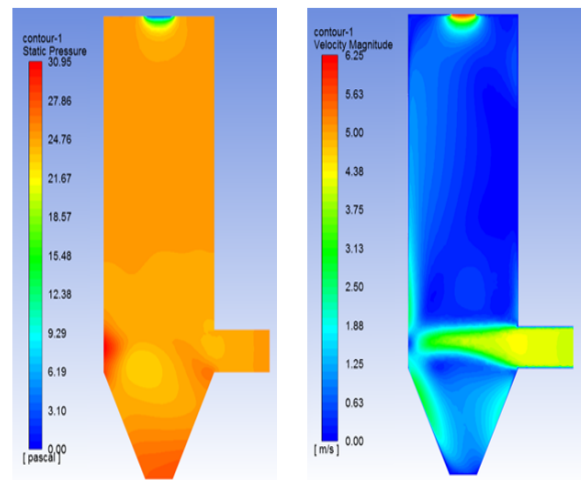

Fig. 5. Contours of pressure (a) and velocity (b) in reference geometry.

a)

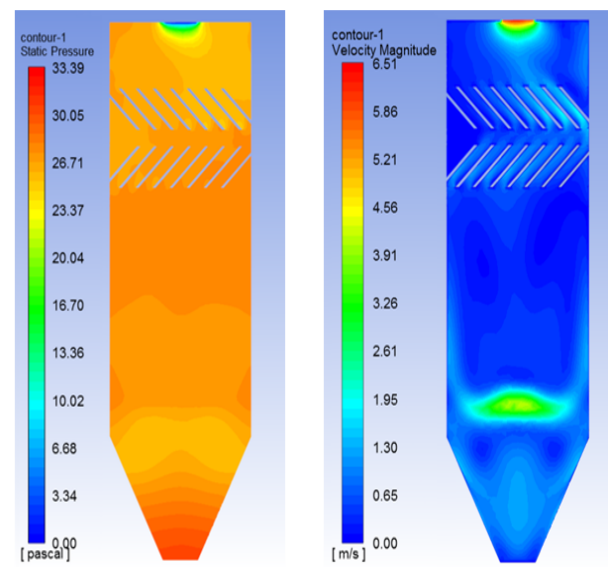

Fig. 6. Contours of pressure (a) and velocity (b) for the case with double demister.

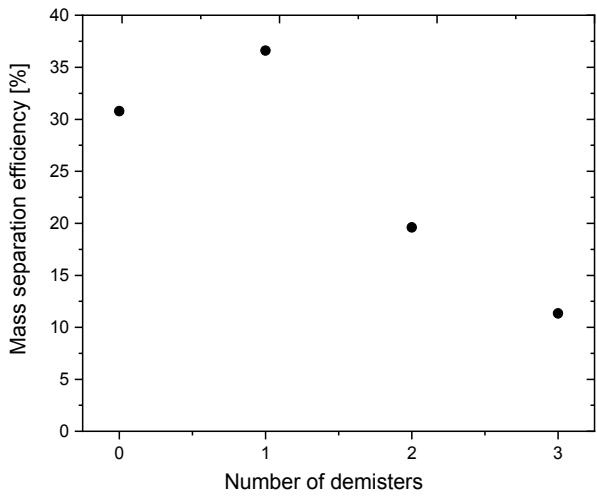

Fig. 7. Number of rows in demister impact on mass separation efficiency.

In Fig. 8 there are presented registered passes of particles through selected locations in the scrubber (the planes $p$ shown in Fig. 4). The effect of separation efficiency, for the whole range of injected particle diameters, can be observed be comparing the number of passes on the inlet and gas outlet. On these locations, each particle should be registered only once, while on the planes $p_{1}, p_{2}, p_{3}$ 
multiple passes were possible. Therefore the detected number of passes on the sampling planes can be higher than that on the inlet. Indeed, the results showed that a single particle can flow through the sampling plane several times during the time of simulation, which indicates that in these regions particles flow alternately upward and downward. The mass efficiency of dust collection was calculated by comparing the total particle mass on the inlet and gas outlet after the $10 \mathrm{~s}$ of flow simulation.
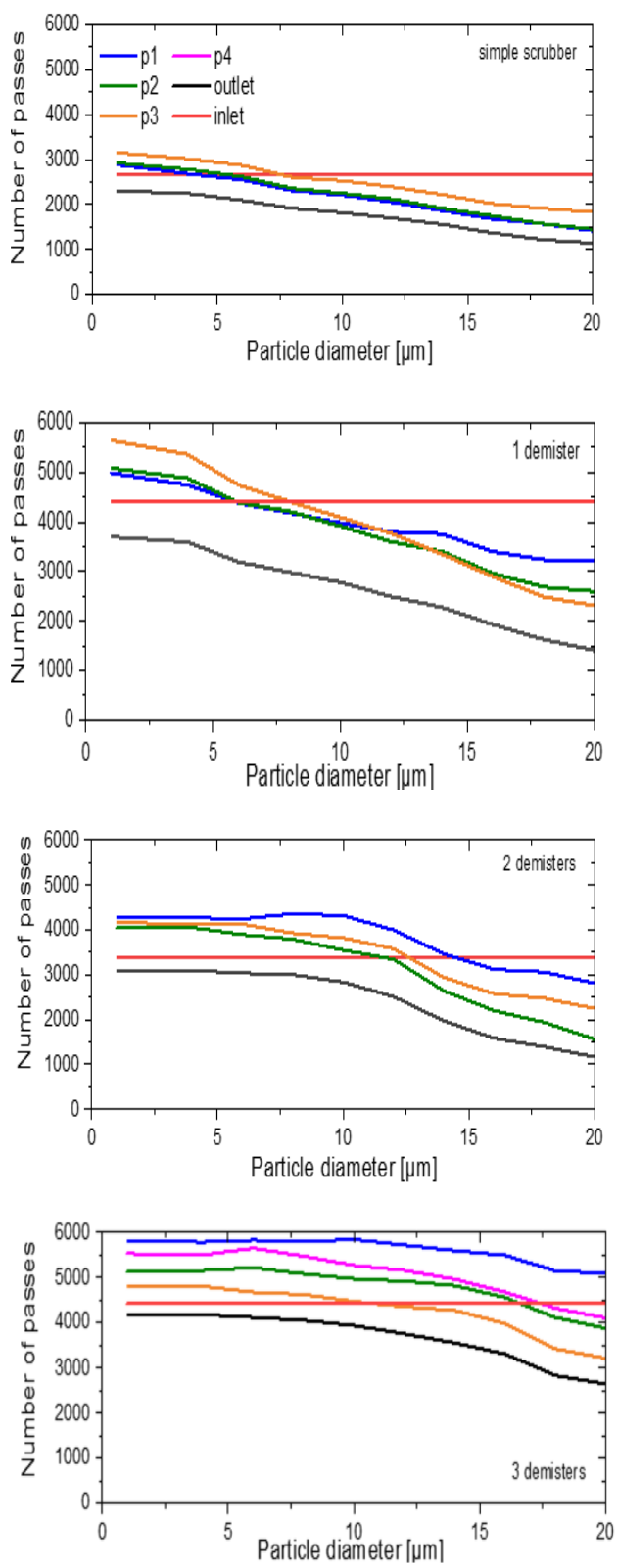

Fig. 8. Number of particle passes through each sample plane, inlet and gas outlet for the reference case and the cases with single, double and triple demisters.
During the computations, the particle vertical component of velocity and the time instant in which the particle passed through the planes $\mathrm{p}_{1}, \mathrm{p}_{2}, \mathrm{p}_{3}$ were also sampled. These results are presented in Fig. 9 and Fig. 10.

There can be observed in Fig. 9 that both negative and positive vertical component of velocity values are present, which proves that the particles flow upwards and downwards. Figure 10 presents the effect of mist eliminator on time instant in which the particle flows through the sampling plane. It is visible that the presence of mist eliminator increases the time in which the particle moves through the scrubber geometry.
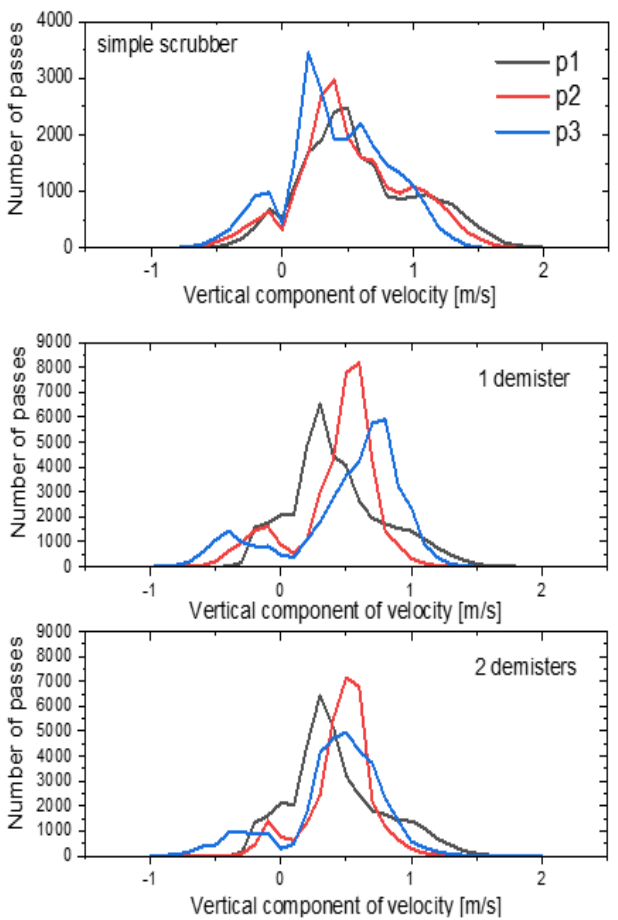

Fig. 9. Particle vertical component of velocity detected on sampling planes.

\section{Results OF WeT Dust EXTRACTION EFFICIENCY FOR DIFFERENT DROPLET DIAMETERS}

After the first part of the numerical analysis of several scrubber geometries, without the presence of droplets, it was determined that the case with single demister has the highest dust collection efficiency. The next calculations included the effects of collision and coalescence. At first the reference case was calculated, without collector droplets injected into the scrubber chamber. It was determined that in this case the dry scrubber quantitative efficiency was equal to $\eta_{\text {dry }}=0.434$. This efficiency was defined as a ratio of the quantity of collected contamination particles to their total quantity, introduced to the system.

Then, the collector droplets were injected and their 
size and quantity had to be selected properly. It is required that the collector droplets cannot be carried by the flow to the upper section of the scrubber and its outlet so their terminal velocity has to be higher than the predicted vertical component of velocity in the scrubber middle section, below the demister (Fig. 11). According to Tab. 4, the droplets larger than $100 \mu \mathrm{m}$ fulfill these conditions so they were used in further numerical simulations.
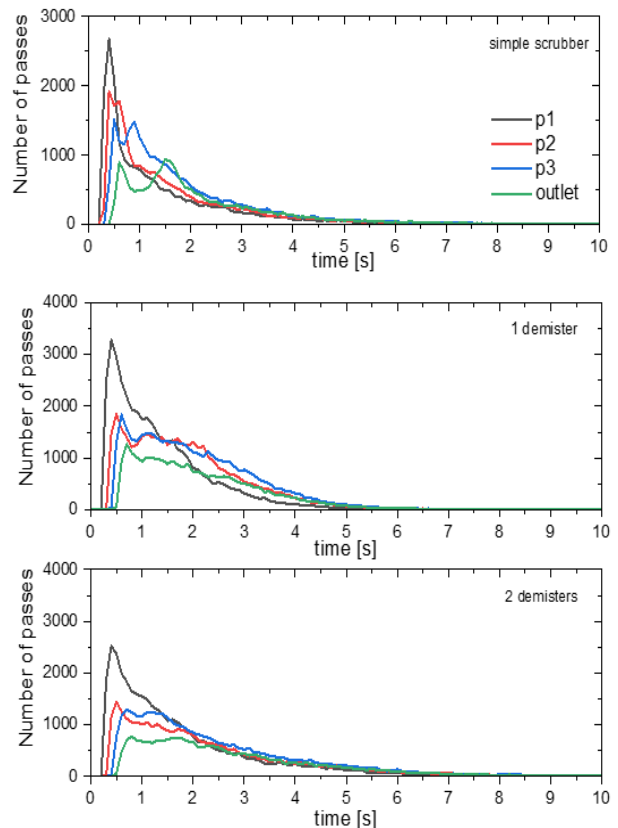

Fig. 10. Detected time of particle pass through the sampling plane.

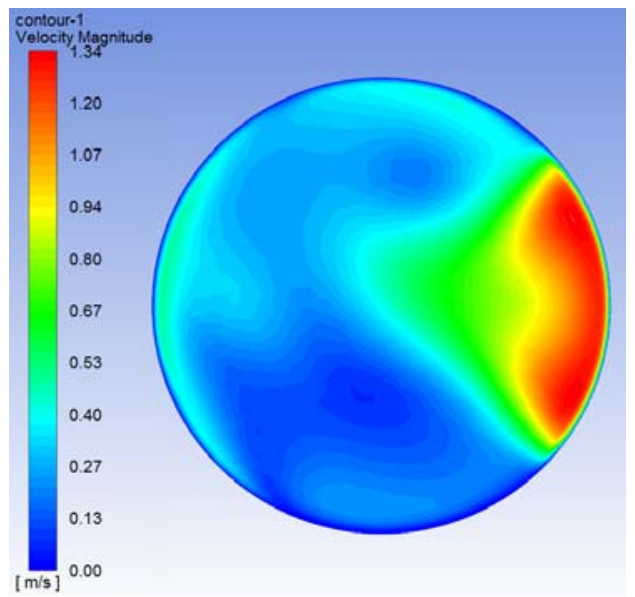

Fig. 11. Vertical component of gas velocity in the middle section of the scrubber, below the demister.

The simulations with water droplet injection were performed for the range of diameters from $100 \mu \mathrm{m}$ to $200 \mu \mathrm{m}$ and presented mass flow rates of the injection. The results of collection efficiency obtained from numerical simulation were compared with the results from Eq. (20) as shown in Tab. 5 and Fig. 12, on which the quantitative efficiency of dust collection for several contamination diameter fractions are depicted.

According to the numerical solution, droplets of $100 \mu \mathrm{m}$ diameter were carried away by the air flow through the outlet and therefore they are not included in Tab. 5. It was concluded that the simplified analytical method, represented by Eq. (20), is consistent with CFD calculation results. According to Table 5, the differences of separation efficiency should not exceed $10 \%$ level (see also Fig. 12).

Table 7 Wet scrubber collection efficiency

\begin{tabular}{|c|c|c|c|c|}
\cline { 2 - 5 } & \multirow{2}{*}{$\begin{array}{c}\text { Injection } \\
\text { mass flow } \\
{[\mathrm{kg} / \mathrm{s}]}\end{array}$} & \multicolumn{3}{|c|}{ Droplet diameter $[\mu \mathrm{m}]$} \\
\cline { 2 - 5 } CFD & 0 & \multicolumn{3}{|c|}{$43.40 \%$} \\
\cline { 2 - 5 } & 0.1225 & $61.96 \%$ & $60.76 \%$ & $59.89 \%$ \\
\cline { 2 - 5 } & 0.6125 & $83.22 \%$ & $82.52 \%$ & $82.81 \%$ \\
\hline \multirow{3}{*}{ Eq. (20) } & 0 & \multicolumn{3}{|c|}{$43.40 \%$} \\
\cline { 2 - 5 } & 0.1225 & $63.08 \%$ & $60.57 \%$ & $58.62 \%$ \\
\cline { 2 - 5 } & 0.6125 & $93.31 \%$ & $90.71 \%$ & $88.18 \%$ \\
\hline
\end{tabular}

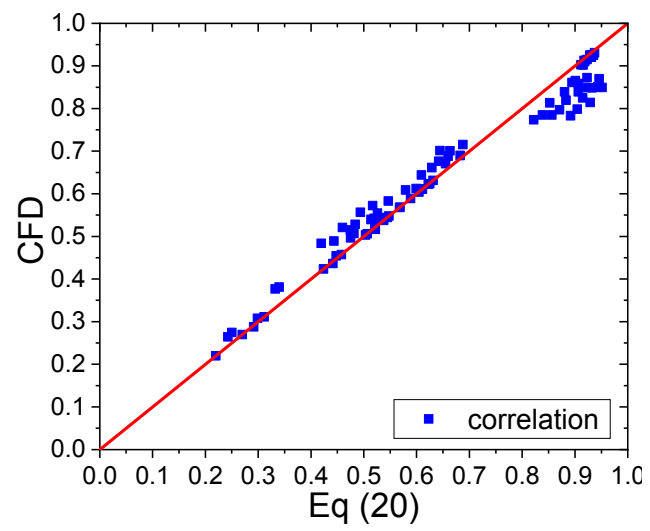

Fig. 12. Comparison of collection efficiency obtained from CFD and Eq. (20).

Although the CFD calculations showed that the impact of collector droplet diameter on separation is not as significant as predicted by the Eq. (20), both methods proved that properly chosen injection mass flow rate results in separation efficiency on desired level. The efficiency of the contamination removal increases with the contaminants diameter (see in Fig. 13). Figure 13 shows the CFD calculations results for the case with single demister and experimental results of Wrzesinska and Witmann (2009), which are in good agreement. Wrzesinska and Witmann (2009) in their experimental study used liquid flow rate equal to $0.06 \mathrm{~kg} / \mathrm{s}$, and obtained better results, what might be a results of the application of centrifugal drop separator and concentric nozzle arrangement. The Fig. 14 shows the results of CFD calculations with water injection for the case with double mist eliminator. The collection efficiency is slightly higher than for the 
case with single mist eliminator. In this particular case, placing an additional demister improves the total mass collection efficiency but only by a few percent and, does not seem to be a profitable option due to more complex design.

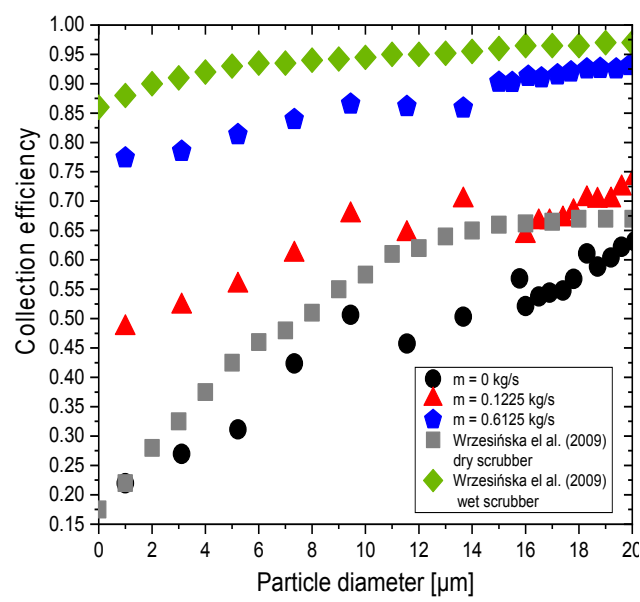

Fig. 13. CFD results for the case with single mist eliminator. Efficiency of dust removal in the scrubber for collector droplet size of $200 \mu \mathrm{m}$ and three values of injection mass flow rate compared with experimental measurement Wrzesinska and Witman (2009).

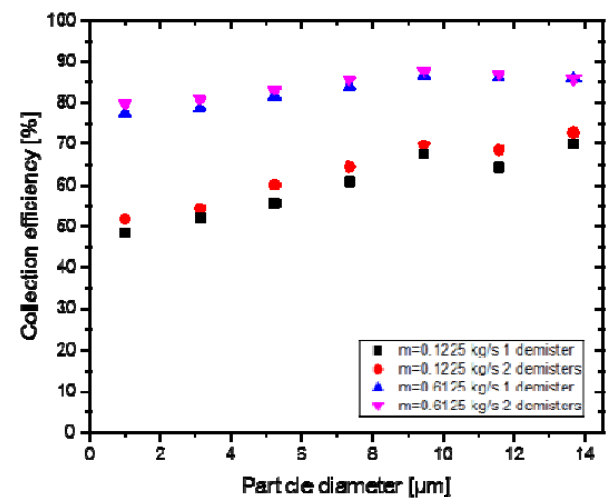

Fig. 14. The CFD results for the case with double mist eliminator compared with results for single mist eliminator. Efficiency of dust removal in the scrubber for collector droplet size of $200 \mu \mathrm{m}$ and three values of injection mass flow rate.

\section{CONCLUSION}

Spray scrubbers are commonly used for gas purification. Their main advantage is simplicity of the construction. However, the phenomena occurring inside of them, like collision of droplets and particles in turbulent flow regime, can be quite complex. In order to better understanding of these processes and estimation of dust collection efficiency in the given scrubber geometry, the computational fluid dynamics (CFD) methods have been used.

The performed numerical simulations consisted of two parts. At first, the effect of scrubber geometry on dust collection efficiency was investigated without collector droplets introduced to the system. Then the second part of CFD analysis included the presence of droplets. Several geometries of the scrubber were analyzed. Simulations were performed by solving the steady state Reynolds Averaged Navier-Stocks Equation (RANS), initially for single phase gas flow and subsequently for unsteady flow with dust particle tracking. According to Mundo et al. (1995), for predicted range of droplet velocity and diameters, every contact with a wall will result in droplet deposition. Therefore, the boundary condition of reflection with total velocity extinction have been set. The preliminary calculations without droplets showed that among tested cases, the scrubber geometry with one mist eliminator leads to optimal dust collection efficiency. For geometry with more than one mist eliminator, the gas flow accelerates in each demister, which leads to higher velocities around the top demister vanes (Fig. 6b). It is caused by reduction of flow cross section area in the demister and by centrifugal force. Further CFD calculations, which included the presence of collector droplets were also done. The mechanisms of collision and coalescence were described and applied in these simulations. The calculations for single and double mist eliminator were performed. The results showed a slight increase in separation efficiency in the case with the second mist eliminator although the main disadvantage of such arrangement is increase of complexity. The calculations were performed for droplet diameters from $100 \mu \mathrm{m}$ to $200 \mu \mathrm{m}$ and several droplet injection mass flow rates. According to the theoretical predictions, for the selected range of injected droplet diameters, all collisions with contamination droplets should result in coalescence (Fig. 3). The separation efficiency was obtained from CFD simulations and compared with Equation (20). The results were consistent and the difference did not exceed the $10 \%$ level. The separation efficiency was determined for contamination diameter ranging from $1 \mu \mathrm{m}$ to $20 \mu \mathrm{m}$ and the results are compatible with experimental data from literature (Schifftner and Hesketh 1996; Wrzesinska and Witman 2009).

\section{ACKNOWLEDGEMENTS}

The work was carried out as a part of the TechRol project - the strategic research and development program of the Polish National Center for Research and Development (NCBiR) entitled "Natural environment, agriculture and forestry BIOSTRATEG". No. 3/344128/12/NCBiR/2017.

\section{REFERENCES}

Abdoulmouminea, N., S. Adhikari, A. Kulkarni and S. Chattanathan (2015). A review on biomass gasification syngas cleanup, Applied Energy (155), 294-307.

Codolo, M. C., W. A. Bizzo (2013). Experimental study of the SO 2 removal efficiency and 
A. Tomaszewski et al. / JAFM, Vol. 13, No. 4, pp. 1055-1066, 2020.

volumetric mass transfer coefficients in a pilotscale multi-nozzle spray tower. International Journal of Heat Mass Transfer (66), 80-89.

Jafari, M., A. Matin, A. Rahmati, M. Azari, L. Omidi, S. Hosseini and D. Panahi (2018). Experimental optimization of a spray tower for ammonia removal. Atmospheric Pollution Research (9), 783-790.

Javed, K., T. Mahmud and E. Purba (2006). Enhancement of mass transfer in a spray tower using swirling gas flow. Chemical Engineering Research and Design (84), 465-477.

Koller, M., D. Wappel, N. Trofaier and G. Gronald (2011). Test results of CO2 spray scrubbing with Monoethanolamine, Energy Procedia (4), 1777-1782.

Kuntz, J. and A. Aroonwilas (2009). Mass-transfer efficiency of a spray column for $\mathrm{CO} 2$ capture by MEA, Energy Procedia (1), 205-209.

Lapin, A. and A. Lübbert (1994). Numerical simulation of dynamics of two-phase gas flow in bubble columns, Chemical Engineering Science (49), 3661-3674.

Marocco, L. (2010). Modelling of the fluid dynamics and $\mathrm{SO} 2$ absorption in a gas-liquid reactor. Chemical Engineering Journal (162), 217-226.

Marocco, L. and F. Inzoli (2009). Multiphase Euler-Lagrange CFD simulation applied to Wet Flue Gas Desulphurization technology. International Journal of Multiphase Flow (35), 185-194.

Morsi, S. A. and A. J. Alexander (1972). An investigation of particle trajectories in twophase flow systems, Journal of Fluid Mechanics (55), 193-208.

Mundo, C., M. Sommerfeld and C. Tropea (1995). Droplet-Wall Collisons Experimental Studies of the Deformation and Breakup Process. International Journal of Multiphase Flows (21), 151- 173.

O'Rourke, P. J. (1981). Collective Drop Effects on Vaporizing Liquid Sprays. Ph. D. thesis, Princeton University, Princeton, New Jersey, USA.

Schifftner, K. C. and H. E. Hesketh (1996). Wet Scrubbers. Second Edition, CRC Press.

Svarovsky, L. (1981). Solid - Gas Separation, First Edition, Elsevier.

Wang, S., J. Wang, Ch. Song, and J. Wen (2019). Numerical investigation on urea particle removal in a spray scrubber using particle capture theory. Chemical Engineering Research and Design (145), 150 - 158.

Warych, J. (1998). Gas purification. Processes and apparatus. (in Polish). Wydawnictwa Naukowo - Techniczne, Warszawa.

Woolcock, P., R. C. Brown (2013). A review of cleaning technologies for biomass-derived syngas, Biomass and Bioenergy (52), 54-84.

Wrzesinska, B. and S. Witman (2009). Wet Dust Removal in a Scrubber with the Colliding Streams (in Polish), Rocznik Ochrona Srodowiska, wyd. Srodkowo-Pomorskie Towarzystwo Naukowe Ochrony Srodowiska (11), $889-898$.

Yeh, N. K. and G. T. Rochelle (2003) Liquid-phase mass transfer in spray contactors. AIChE Journal (49), 2363-2373.

Zhen, Ch., W. Haiming, Z. Jiankun and Y. Chamgfu (2017). Experimental and numerical study on effects of deflectors on flow field distribution and desulfurization efficiency in spray towers. Fuel Processing Technology (162), $1-12$. 